\title{
Environmental Impact Assessment and Source Identification of Total Suspended Particulate Matter and Some Elements Emitted from a Workplaces in Jordan
}

\author{
Omar Ali Al Khashman* \\ Department of Environmental Engineering, College of Engineering, Al-Hussein Bin Talal University, Jordan
}

*Corresponding author: Omar Ali Al Khashman, Department of Environmental Engineering, College of Engineering, Al-Hussein Bin Talal University, Jordan.
Received Date: September 27, 2019

Published Date: October 03, 2019

\begin{abstract}
The objective of the present study was to assess the extent and severity of atmospheric particulate concentrations and metal concentration in dust, street dust and soil in the Aqaba Industrial Estate (AIE). Samples of dust, street dust and soil were analyzed for their contents of atmospheric particulate matter and elements $(\mathrm{Fe}, \mathrm{Cu}, \mathrm{Ni}, \mathrm{Pb}, \mathrm{Zn}, \mathrm{Mn}$ and $\mathrm{Cr}$ ) after digestion with nitric acid. This study shows that analyzed major sources and magnitude of elements pollution. The mean concentrations of the elements were as follows: $\mathrm{C}_{\mathrm{Fe}}>\mathrm{C}_{\mathrm{Pb}}>\mathrm{C}_{\mathrm{Zn}}>\mathrm{C}_{\mathrm{Cr}}>\mathrm{C}_{\mathrm{Mn}}>\mathrm{C}_{\mathrm{Cu}}$ and $\mathrm{C}_{\mathrm{Cd}}$ where $\mathrm{C}$ stands for concentration. $\mathrm{Zn}, \mathrm{Cd}$ and $\mathrm{Pb}$ were in high levels in the area close to the workplace, while the chromium level was low. This study indicates that all of the elements are concentrated on the surface soil, and decreased in the lower part of the soil, this due to reflect their mobility and physical properties of soil and its alkaline $\mathrm{pH}$ values. The results indicated that the mean concentrations of elements in the dust, street dust and soil were too low to yield any known environmental health effects. The use of factor analysis is determined three groups of elements that differ in their distribution. The first of these components is polluted soil, which occurs distributed inside the study area. The second is the unpolluted soil, which occurs mostly in the study. The third factor represents the physicochemical sources of the variability, and this factor is not significant.
\end{abstract}

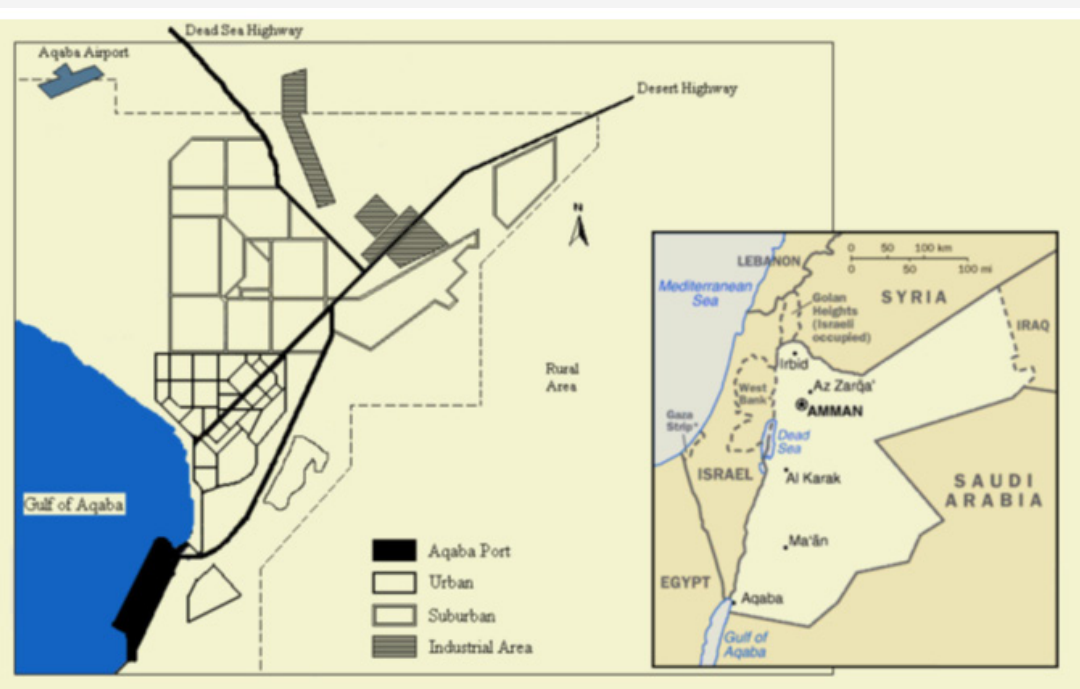

Figure 1: Location map of the study area. 
The study area is located at the north shore of the Gulf of Aqaba, in the south-western part of Jordan. It is about $51 \mathrm{~m}$ above the sea level and bounded by latitude $\left(29^{\circ} 33^{\prime} \mathrm{N}\right)$ and longitude $\left(35^{\circ} 0^{\prime}\right.$ E) (Figure 1). It is a coastal city with a population of 120,000 [1]. The main industrial activities in Aqaba city are Jordan Phosphate Company was established in 1985, cement, petroleum industry, Jordan fertilizer industries plant and some shells. The Red Sea port of Aqaba is an important commercial shipping center. Aqaba city climate is very hot in the summer and warm in the winter and is characterized by an extremely small amount of precipitation, which is around $17.0 \mathrm{~mm} /$ year [2]. Minimum temperature in the study area is $9.7{ }^{\circ} \mathrm{C}$ in January and $26.3{ }^{\circ} \mathrm{C}$ in July [3]. The investigated area is located in the northwest part of the Arabian plate, whereas most of Jordan is located within the stable part of the plate.

\section{Samples Collection and Analysis}

Forty-eight TSP (Total Suspended Particles) samples to analyze 7 elements including $\mathrm{Fe}, \mathrm{Pb}, \mathrm{Zn}, \mathrm{Cu}, \mathrm{Cr}, \mathrm{Mn}$ and Ni were collected

in the period of June 2016-August 2016 using a High-Volume Air Sampler (Andersen) with a flow rate $50 \mathrm{~m}^{3} \mathrm{~h}^{-1}$ equipped with filter holders. Total suspended particulate (TSP) was collected onto Whatman GF/A20 cm x $25 \mathrm{~cm}$ fiberglass filters [4,5]. The sampler was placed at a height of about $2 \mathrm{~m}$ for 24 hours periods inside working areas where workers spend most of their working times 8-12 hours/day. The sampler was run continuously for a period of 24 hours and was turned off for a period of 24-72h before the sampler was operated again [4]. Care was taken in collecting filters in order to avoid any contamination. At the end of the sampling collection, the filter paper was removed and dried. The concentration of TSP was determined gravimetrically by weighting the filters prior to and after collecting samples using an analytical balance with a reading precision of $\pm 10 \mu \mathrm{g}$ and analyze for the presence of elements $\mathrm{Fe}, \mathrm{Pb}$, $\mathrm{Zn}, \mathrm{Cu}, \mathrm{Cr}, \mathrm{Mn}$ and $\mathrm{Ni}$ [6]. The samples were selected on the basis that the collected samples would be representative of the worst pollution conditions in the area. Prior to dust sample collection, preparatory cleaning procedures were applied to filters. Several methods were also used to determine the elements by Fang [7], Paode et al. [8], Yi et al. [9], Odabasi et al. [10], Tasdemir et al. [11]. The whole weighted filter paper was digested in a Pyrex beaker with $3 \mathrm{~N}$ nitric acid (analytical grade) for an hour on a hot plate at $90{ }^{\circ} \mathrm{C}$. The sample was then filtered through a glass-filter paper (Whatman GF/A of 110 mm-diameter). The volume was then made up to $100 \mathrm{ml}$ with de-ionized water. The extracts thus obtained were filtered and stored in polypropylene bottles at refrigerator 4 ${ }^{\circ} \mathrm{C}$ until analysis. The full analytical procedure was also completed for a blank [4]. All glassware used in the extraction procedures was initially rinsed with soap, washed with tap water and rinsed with distilled water, and soaked in $1 \% \mathrm{HNO}_{3}(\mathrm{v} / \mathrm{v})$ overnight to remove any contamination by elements; the glassware was then washed thoroughly with distilled and de-ionized water. All chemicals used were analytical reagent-grade. The elements (Fe, $\mathrm{Pb}, \mathrm{Zn}, \mathrm{Cu}, \mathrm{Cr}, \mathrm{Mn}$ and $\mathrm{Ni}$ ) were determined by using a Shimadzu atomic absorption spectrophotometer (model AA-6200).

\section{Results and Discussion}

\section{Total suspended particulate (TSP) concentrations}

Particulate samples collected from both the indoor work environment of 48 industries and the 18 houses located nearby the Aqaba workplace. Higher values of TSP are observed in the samples collected from mechanical and electrical workplace, the highest value is $137,78 \mathrm{ng} \mathrm{m}^{-3}$. The high levels of TSP are mainly due to the soil re-suspension caused by the dry weather and wind, traffic and industrial emissions.

\section{Trace element concentration in air particulate}

Table 1 presents values of the elements in air particulate matter in the study area. Lead in urban and industrial areas is emitted by different sources and each of these industries emits lead with different form [11]. Looking at Table 1, it can be seen that lead showed concentrations ranging from $133.7 \mathrm{mg} \mathrm{kg}^{-1}$ inside the workplace to $2.58 \mathrm{mg} \mathrm{kg}^{-1}$ inside the houses nearby the workplace. These values are much less than the lead mean limit of the indoor air quality standard $\left(50,000 \mathrm{ngm}^{-3}\right)$. They are also lower than the values reported at Sohar Industrial Estate (SIE) in Oman (262.8 ngm $^{-3}$ ) [4]. The highest lead concentrations (133.7 $\left.\mathrm{mg} \mathrm{kg}^{-1}\right)$ in the dust samples has been found in samples collected in smelters, ovens and mechanical sites, but the lowest concentrations are found in samples collected in construction materials. Lead emissions are mainly from vehicle emissions and residential heating. In addition, lead emitted by traffic may be associated with aerosols as $\mathrm{PbSO}_{4}$. $\left(\mathrm{NH}_{4}\right) 2 \mathrm{SO}_{4}[11,12]$. This is result by a liquid phase reaction process occurring after coagulation of traffic emitted lead bromochloride, $\mathrm{PbBrCl}$, with ammonium sulphate, present at higher relative humidity as solution droplets. Moreover, wooden furniture manufacturing is widely distributed in the study area. However, most of the lead values emitted from batteries, car services, metal smelting and mechanical and electrical materials. The range of the mean of copper in dust samples was (55.6 mg kg-1) is found in dust samples found at work place of ovens, smelters, and mechanical sites, but the lowest values are found at the work place of the furniture and woody industry. According to Al-Khashman [13] $\mathrm{Zn}$ and $\mathrm{Cu}$ may be derived from mechanical abrasion of vehicles, as they are used in the production of brass alloy itself and come from brake linings, oil leak sumps and cylinder head gaskets. Zinc compounds are usually used for wheel manufacturing, metal alloys, abrasion of vehicle, ceramic, plastic materials and pesticides and fertilizers $[14,15]$. The contents of zinc in the dust samples ranged from $849 \mathrm{ngm}^{-3}$ is found in dust samples found in workplace of the car service to $221 \mathrm{ngm}^{-3}$ in the dust samples of the construction materials. The highest $\mathrm{Zn}$ values are found in smelters, oven and car services, and the lowest concentrations are measured in furniture and wood industry. The nickel values measured at all sample sites remained below the natural limits $\left(5.9-1.5 \mathrm{mgkg}^{-1}\right.$ dry soil). The highest concentration of nickel is found at car service, smelters, ovens and mechanical and electrical sites, but the lowest value is measured in construction materials. The high value of nickel may be due to the industrial activities in the workplace, such as silver 
working in the area, tire wear and the source of nickel in dust may originate from traffic and corrosion of cars [15]. Iron is one of the principle elements in the earth crust and is mainly associated with coarse atmospheric particles, if associated with other sources it is generally deposited in the neighborhood of the emission sources [15-17]. Iron is found to be in high concentrations in most of dust samples. This can be attributed to the soil in the study area being

Table 1: Mean levels of elements in indoor dust; all values were in $\mathrm{mg} \mathrm{kg}^{-1}$.

\begin{tabular}{|c|c|c|c|c|c|c|c|}
\hline Product & $\mathbf{P b}$ & $\mathbf{Z n}$ & $\mathbf{C u}$ & $\mathbf{C r}$ & $\mathbf{M n}$ & $\mathbf{F e}$ & $\mathbf{N i}$ \\
\hline Car service & $56.5 \pm 18.1$ & $65.3 \pm 6.9$ & $23 \pm 1.7$ & $3.4 \pm 0.48$ & $35 \pm 2.2$ & $96.5 \pm 45.1$ & $5.9 \pm 5.1$ \\
\hline Furniture and Wood & $8.35 \pm 1.8$ & $16.4 \pm 14.2$ & $8.3 \pm 2.4$ & $3.1 \pm 0.7$ & $18 \pm 3.3$ & $80.4 \pm 35.4$ & $5.0 \pm 2.0$ \\
\hline Steel and non-Steel & $24.5 \pm 5.7$ & $38.5 \pm 13.1$ & $11.5 \pm 4.0$ & $10 \pm 4.3$ & $44 \pm 5.1$ & $92.5 \pm 38.1$ & $2.3 \pm 2.2$ \\
\hline Ovens and Smelters & $133.7 \pm 8.2$ & $54.6 \pm 15.7$ & $55.6 \pm 8.3$ & $24 \pm 2.8$ & $62 \pm 5.2$ & $87.6 \pm 31.2$ & $5.6 \pm 1.9$ \\
\hline Mechanical and Electrical & $42.5 \pm 8.7$ & $24.5 \pm 64.5$ & $18.7 \pm 5.7$ & $11.5 \pm 3.1$ & $8.0 \pm 1.5$ & $84.7 \pm 11.4$ & $4.5 \pm 4.0$ \\
\hline Construction materials & $35.2 \pm 11.4$ & $9.5 \pm 76.5$ & $8.52 \pm 10.9$ & $7.5 \pm 4.1$ & $8.5 \pm 2.0$ & $77.1 \pm 22.1$ & $1.5 \pm 1.5$ \\
\hline Residential area (18 houses) & $2.58 \pm 5.3$ & $3.5 \pm 12.5$ & $2.28 \pm 3.1$ & $2.2 \pm 5.6$ & $4.5 \pm 4.1$ & $15.4 \pm 17.5$ & $1.7 \pm 3.1$ \\
\hline
\end{tabular}

\section{Conclusion}

The chemical composition of three types of materials (dust, street dust and soil) in this study helped to knowledge and explains the distribution of elements within the study area. The results showed relatively low concentrations of $\mathrm{Fe}, \mathrm{Cu}, \mathrm{Ni}, \mathrm{Pb}, \mathrm{Zn}, \mathrm{Mn}$ and $\mathrm{Cr}$. However, the mean concentrations of element in the materials at AIE were too low to yield any known health effect $[19,20]$. The results of this study would help to identify elements from different sources, estimate indoor elements values in workplaces and houses around this area. Moreover, the mean concentrations of elements in the dust, street dust and soil were too low to yield any known environmental health effects. There are two possible sources of elements ( $\mathrm{Fe}, \mathrm{Cu}, \mathrm{Ni}, \mathrm{Pb}, \mathrm{Zn}, \mathrm{Mn}$ and $\mathrm{Cr}$ ) anthropogenic and industrial activities from the workplace in AIE. Significant contribution from industrial sources at AIE was evident at nearby places.

\section{Acknowledgement}

None.

\section{Conflict of Interest}

No conflict of interest.

\section{References}

1. Department of Statistics (2004) Internal report. Amman, Jordan.

2. Al Khashman OA (2007a) Determination of metal accumulation in deposited street dusts in Amman, Jordan. Environmental Geochemistry and Health 29(1-10): 1-10.

3. Department of Meteorology (2004) Internal report "data and files of the department of meteorology". Amman. Jordan.

4. Abdul Wahab SA, Yaghi B (2004) Total suspended dust and heavy metal levels emitted from a workplace compared with nearby residential houses. Atmospheric Environment 38(5): 745-750.

5. Tasdemir Y, Kural C, Cindoruk, Vardar N (2006) Assessment of trace elements concentrations and their estimated dry deposition fluxes in an urban atmosphere. Atmospheric Research 81: 17-35.

6. Cancio JL, Castellano AV, Hernandez M, Bethencourt RG, Ortega EM (2008) Metallic species in atmospheric particulate matter in Las Palmas de Gran Canaria. Journal of Hazardous materials 160(2-3): 521-528. rich in iron content. The highest iron concentration is found at the workplace of car service, while the lowest value of iron is found at the workplace of smelters, ovens and mechanical sites. The high value of iron at the workplace of car service proved that the availability of the anthropogenic factor existing in the dust. This includes wear of brake linings and corrosion, and wear of vehicles [18].

7. Fang GC (1992) A study of mass size distributions and particle deposition velocities in ambient air. Ph.D. Thesis of Illinois Institute of Technology. Chicago, Illinois. 220pp.

8. Paode RD, Sofuoglu S, Sivadechathep J, Noll KE, Holsen TM, et al. (1998) Dry deposition fluxes and mass size distributions of $\mathrm{Pb}, \mathrm{Cu}$, and $\mathrm{Zn}$ measured in southern Lake Michigan during AEOLOS. Environ Sci Techno 32(11): 1629-1635.

9. Yi SM, Shahin U, Sivadechathep J, Sofuoglu SC, Holsen TM (2001) Overall elemental dry deposition velocities measured around Lake Michigan, Atmospheric Environment 35(6): 1133-1140.

10. Odabasi M, Muezzinoglu A, Bozlaker A (2002) Ambient concentrations and dry deposition fluxes of trace elements in Izmir, Turkey. Atmospheric Environment 36: 5841-5851.

11. Al Masri MS, Al Kharfan K, Al Shamali K (2006) Speciation of Pb, Cu and $\mathrm{Zn}$ determined by sequential extraction for identification of air pollution sources in Syria. Atmospheric Environment 40: 753-761.

12. Harrison M (1990) Pollution Causes, Effects and control, second edition. Royal Society of Chemistry, UK.

13. Al Khashman OA (2007b) The investigation of metal concentrations in street dust samples in Aqaba city, Jordan. Environmental Geochemistry and Health 29(3): 197-207.

14. Akhter MS, Madany IM (1993) Heavy metals in street dust and house dust in Bahrain. Water, Air and Soil Pollution 66(1-2): 111-116.

15. Al Khashman O (2004) Heavy metal distribution in dust, street dust and soils from the workplace in Karak Industrial Estate, Jordan. Atmospheric Environment 38(39): 6803-6812.

16. Berg T, Royset O, Steinnes E, Vadset M (1995) Atmospheric trace element deposition: Principle Component Analysis of ICP-MS data from moss samples. Environmental Pollution 88(1): 67-77.

17. Carreras HA, Pignata ML (2002) Biomonitoring of heavy metals and air quality in Cordoba city, Argentina, using transplanted lichens. Environmental Pollution 177(1): 77-87.

18. Thomson NR, Mc Bean EA, Snodgrass W, Monstrenko IB (1997) Highway storm water runoff quality, Development of surrogate parameter relationships. Water, Air and Soil Pollution 94(3-4): 307-347.

19. Biswas TD, Mukherjee SK (1988) Soil Science Textbook. Total McGrawHill Publishing Company Limited, New Delhi.

20. Brady JE (1982) General Chemistry, $3^{\text {rd }}$ edition, John Wiley \&Sons, New York. 